\title{
Analysis on the Effectiveness of Financial Support for Ecological Poverty Alleviation in Guizhou
}

\author{
Hongmei Zhang ${ }^{1,2,3}$, Zhehao Zhang ${ }^{1,2,3}$ \\ ${ }^{1}$ Finance College of Guizhou University of Finance and Economics, Guiyang 550025, China \\ ${ }^{2}$ Guizhou Research Institute of scientific and technological innovation and venture investment, \\ Guiyang 550025, China \\ ${ }^{3}$ Guizhou Research Institute for urban and economic development, Guiyang 550025, China
}

\section{贵州省金融支持生态扶贫的成效分析 \\ 张红梅 ${ }^{1,2,3}$, 张锗豪 ${ }^{1,2,3}$ \\ ${ }^{1}$ 贵州财经大学金融学院, 贵阳 550025, 中国 \\ 2 贵州科技创新创业投资研究院, 贵阳 550025 , 中国 \\ ${ }^{3}$ 贵州城镇与经济发展研究院, 贵阳 550025, 中国}

\begin{abstract}
During the 13th Five-Year Plan period, China entered the fight against poverty and put forward a strategy for ecological poverty alleviation. Guizhou, as an underdeveloped area in the western part of China, is a key area for implementing ecological poverty alleviation and win-win strategies. In recent years, Guizhou's economy has developed rapidly, and the financial sector has continuously carried out reforms and innovations, laying the foundation for the implementation of the ecological poverty alleviation strategy. This article collects financial deepening rates, ecological expenditures, improvement of residents' lives, and economic development in nine prefectures and cities in Guizhou Province. Through the use of DEA model to analyze the effectiveness of financial support for ecological poverty alleviation, the city of Guizhou is finally drawn Poverty all are ineffective, and their reasons are analyzed from the aspects of
\end{abstract}

financial input support, ecological

environment and policy implementation.

Keywords: Finance, ecological poverty alleviation, DEA

\section{摘要}

十三五期间, 我国进入脱贫攻坚战, 并且提出了生态扶贫战略。贵州作为我国 西部欠发达地区, 是实施生态扶贫打赢攻 坚战的重点区域。近年来贵州省经济发展 迅速, 金融领域不断进行改革创新, 为实 施生态扶贫战略打下了资本基础。本文收 集到贵州省 9 个地州市的金融深化率，生态 财政支出, 居民生活改善, 经济发展等指 标，通过使用 DEA 模型分析金融支持生态 扶贫的成效，最终得出贵州省的地州市生 态扶贫都处于无效程度，并从金融投入支 持, 生态环境与政策推行等方面来分析其 原因。

关键词：金融, 生态扶贫, DEA

1. 引言

自改革开放以来, 中国经济高速发 展, 金融市场随之发展而壮大。随着每次 
政策改革的支持, 金融行业的开放程度越 来越高。十八大召开之后, 习近平总书记 和李克强总理多次在金融工作原则和发展 重点方面做批示, 如发展普惠金融和绿色 金融; 做好金融工作回归本源、优化结 构、强化监管的三个重要原则等。随着市 场经济的发展, 金融行业在市场经济中的 地位越来越举足轻重, 起到了资金融通、 流转, 分散风险的作用。金融行业的发展 也作用于国民经济的发展, 促进经济发 展, 改善居民生活质量。

据中国统计年鉴显示, 自 1978 年之 后, 我国经济以高增长率增长发展, GDP 由 3645 亿元人民币（1978）增长至 82 万亿 元人民币（2017）。人均 GDP 由 1027.5 元 人民币（1978）增长至 55527 元人民币 (2017)。伴随中国经济飞速增长的同 时, 是中国金融行业的巨大转变与发展。 1978 年之后, 我国金融行业经历了从单一 到多元的发展。自 80 年代起, 金融行业在 政策上不断进行改革, 金融部门逐步多样 起来, 诸如保险公司, 区域银行, 农村、 城市信用社, 信托公司等金融中介涌现出 来。1994 年是关键的一年, 国家开发银 行、农业发展银行、进出口银行三大政策 性银行相继成立, 标志着我国银行业改革 迈上了新的台阶。金融资产总量由 3257.4 亿元人民币（1978）增加至 200.72 万亿元 人民币（2016），年均增长率 $162 \%$, 居民 日常生活中金融服务的可获得性大大增 加。

贵州省位于我国西南部, 因其地理环 境以及人文因素的特殊性, 贵州省相较于 其他省份发展存在很大的阻力, 属于欠发 达省份, 金融改革起步较晚。2016 年, 贵 州省 GDP 为 26909 亿元人民币, 占全国 GDP 总量的 $1.5 \%$ 。金融机构人民币年末存 款余额 13265.01 亿元，金融机构人民币年 末贷款余额 10104.30 亿元, 占全国比重的 $1.2 \%$ 。值得注意的是, 自十八大召开以 来, 国家出台政策大力支持金融行业改革 发展创新以及进入脱贫攻坚战的关键时 期, 贵州省成为脱贫攻坚战的关键区域, 国家政策的扶持，大量资本流入贵州，使
得贵州省近五年金融行业发展迅速, 其中 银行业是金融行业中关键产业; 基础建设 的投入以及“生态扶贫”措施, 让贵州逐渐摘 掉了“贫困”的帽子 $[1]$ 。

扶贫脱贫工作自改革开放后就在不曾 间断的进行着, 40 年间脱贫工作也取得了 巨大的成就: 中国的贫困人口数量由 2.5 亿 人（1978）减少至 1289 万人（2017）。扶 贫脱贫工作的成功, 依托的是有中国特色 的扶贫开发模式, 其中生态扶贫便是根据 我国生态文明建设情况而创设的中国式扶 贫政策。具体说来是把扶贫工作与保护环 境相结合起来的脱贫模式, 发展经济脱离 贫困的同时进行环保, 坚持“绿水青山就是 金山银山”的思想理念。在这种扶贫观念的 指引下, 贵州省大力发展林下经济产业 [2], 发展循环经济, 发展特色产业, 促进 生态保护与扶贫开发的良性互动, 开发与 保护并重, 在保护生态中发展, 在发展中 保护生态, 并且在最近几年中取得了良好 的成效。

在近年政策的支持下, 贵州省金融行 业发展迅速, 并且脱贫工作方面大力发展 生态扶贫, 并由此形成生态产业, 积极探 索“输血式”扶贫向“造血式”扶贫的转型发展 [3]。考虑到以上背景情况, 本文将研究目 标放在金融与生态扶贫方向, 探索两者之 间的关系: 金融行业的发展支持生态扶贫 的成效。效率分析多用 DEA 分析法 [4], 是 研究有多个“输入变量”和多个“输出变量” 时, 探索其是否有效率的方法。本文选取 贵州省实施生态扶贫产业的所有 9 个地州市 的金融行业“金融深化率”（金融资产 /GDP）与各地政府在生态文明建设财政支 出作为投入指标, 产出指标方面, 选取 GDP, 城镇与农村居民的可支配收入, 最 终得出 DEA 分析成果, 旨在探索金融发展 对生态扶贫工作的成效。

\section{2. 国内外相关文献综述}

关于生态扶贫战略及相关概念, 国内 众多专家学者很早便对其做了研究与探 索, 最早是由沈斌华 (1999) [5]提出的: 生态扶贫, 是从本地区的实际出发, 发展 有特色的产业（林业、草业、药材业和沙 
产业），是贫困地区脱贫的必由之路。杨 文举（2002）[6]最早做出了系统性的阐 述：生态扶贫是指从改变贫困地区的生态 环境入手, 加强基础设施建设, 从而改变 贫困地区的生产生活环境, 使贫困地区实 现可持续发展的一种新的扶贫方式。近年 来专家学者对于生态扶贫如何实践进行了 大量的探索, 而生态扶贫又需要因地制 宜, 扶贫需适应当地状况。查燕, 王惠荣 等 (2012) [7]对宁夏的生态扶贫现状与战 略进行了深入的研究探讨, 提出了宁夏水 资源高效利用, 生态环境良性循环, 生态 移民, 区域特色产业发展和示范带动五大 生态扶贫战略。刘慧, 叶尔肯等（2013）[8] 从中国西部生态环境的脆弱性区域和重要 生态功能区空间分布的关联性分析入手, 对西部地区的生态环境与扶贫工作进行了 深入研究, 得出要以教育为核心的人力资 本发展, 以特色农副产品开发, 特色农产 品品牌建设以及生态移民等意见建议。唐 毓森（2011）[9]对国家级贫困县贵州省毕 节市的现状及贫困原因做了调查分析, 研 究表明贫困主要原因在于超生致贫和自然 灾害致贫, 在反贫困的路径上, 提出了创 新的扶贫模式, 控制人口数量, 转变扶贫 方式等有针对性的措施。

金融发展方面, 为了得到合理的量化 金融发展的指标, 美国经济学家 Goldsmith （1969）首次发表了金融相关比率概念 FIR, 用金融资产/GDP 表示, 由此便一般 将金融上层结构与经济基础结构之间在规 模上的关系用 FIR 表示, 可以将其视为衡 量金融发展的一个指标[10]。加拿大经济学 家 Ronald I. Mckinnon (1973) 进而提出了 新的概念: 货币化率 M2/GDP, 表示社会的 货币化程度, 旨在将流通并用来进行商品 交换的货币表示现阶段社会金融发展程 度, 因此可以作为衡量金融发展的一个指 标。以上两个内容只是近代以来经济学家 为金融发展初步创造的理论, 然而近年金 融行业飞速发展, 随着金融场所, 金融工 具, 金融服务等出现, 金融范畴涵盖的越 来越多, 金融发展理论和概念也在不断的 进步与深化 $[11]$ 。本文将选用金融深化率这
一指标, 通过省年鉴搜集到当前金融资产 与 GDP 等数据, 测评贵州省金融行业发展 现状。

\section{3. 贵州省地级市及县域金融与生态发展 现状}

\section{1 贵州省金融发展状况}

贵州省作为我国的资源和生态大省, 拥有数目可观的能源和自然生态产业。单 单已发现的矿产种类便有 123 种, 木本植物 有 124 种, 还包括很多珍惜的名贵草药。但 是由于地理位置及基础设施薄弱, 并且在 政策上重视晚与实施有迟滞的原因, 致使 贵州省经济金融发展缓慢。

十三五期间, 贵州省抓住政策上加强 对西部贫困地区扶贫支持的力度, 秉承 “稳 中求进、提速转型”理念, 大力发展金融与 经济。金融机构数量稳步增加, 银行业等 金融机构总资产、存贷款额显著提升（表 1) 。

2013 年一2016 年期间, 贵州省商业银 行的数量稳步增加, 平均年增长率 $103.6 \%$, 而外资银行与非银行类金融机构 几乎没有增长, 即在金融机构增长规模 上, 只表现为商业银行数量的增长 (表 2) 。

全省金融机构（主要集中在银行业） 2016 年资金来源与运用合计达到了 22449.89 亿元, 同比增长了 $22.7 \%$, 各项存 款金额同比增长 $22.3 \%$, 其中个人存款为存 款增长率贡献巨大, 同比增长 $15.4 \%$ 。贷款 额 2016 年为 17857.80 亿元, 同比增长 $18.6 \%$, 其中中长期贷款额增长率可观, 达 到 $20.8 \%$ 。

\section{2 贵州省生态扶贫发展状况}

贵州省政府于 2018 年 1 月公布了近四 年（2017-2020）生态扶贫的计划, 重点 任务有十条, 其中着重点在于实施退耕还 林建设扶贫工程和实施森林生态效益补偿 扶贫工程。退耕还林型生态扶贫是十三五 以来逐步发展实施的战略, 指通过改善, 退耕有坡度、有石漠化的耕地, 转而因地 制宜发展核桃, 板栗, 樱桃等特色果林产 业, 并且从政策上按每亩地补贴贫困户的 
表 1 贵州省近四年各类金融机构数量

\begin{tabular}{|c|c|c|c|c|c|}
\hline 指标 & & & 2014 & 2015 & 2016 \\
\hline 银行类 & Banking Institutions & 4581 & 4748 & 4915 & 5102 \\
\hline \#商业银行 & Commercial Banks & 1766 & 2326 & 2654 & 2950 \\
\hline \#外资银行 & Foreign Funded Banks & 1 & 1 & 1 & 1 \\
\hline 非银行类 & Non-Bank Institutions & 6 & 6 & 6 & 7 \\
\hline \#财务公司 & Finance Companies & 5 & 5 & 5 & 5 \\
\hline \#信托公司 & Trust Companies & 1 & 1 & 1 & 1 \\
\hline
\end{tabular}

注：资料来源于贵州银监局

\section{表 2 金融机构人民币各项存贷款余额}

单位: 亿元

(100 million yuan)

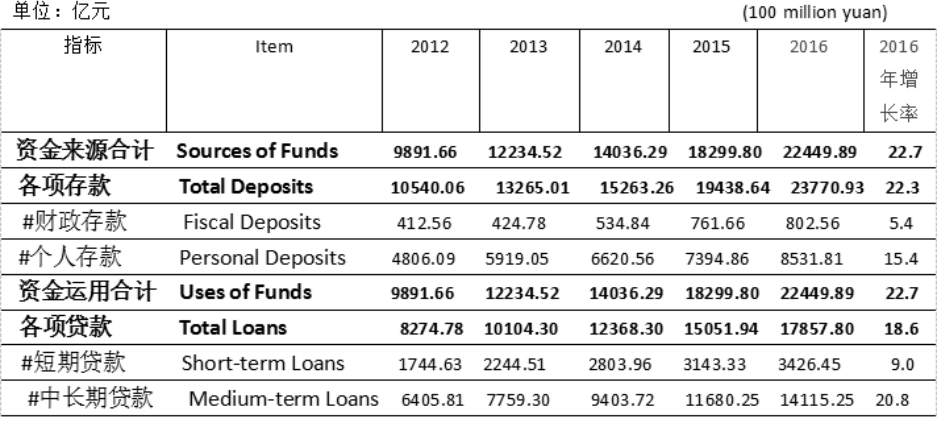

注 : 资料来源于中国人民银行贵阳中心支行

生态扶贫政策。生态扶贫周期长，真正获 得收益存在滞后性, 成效在近年才逐渐展 现出来。表 3 是 2016 年贵州省森林资源情 况, 包括森林总体情况, 退耕还林的实施 情况, 以及森林保护工作情况, 代表着贵 州省政府在退耕还林护林这一生态扶贫政 策方面的实施进展。
表 3 数据显示, 2012 年至 2016 年森林 面积逐年温度增加, 年均增长率约为 $102 \%$, 其中实施退耕还林工程虽然相比于 造林数量占比较小, 但是还在逐步开始进 行, 退耕还林政策在实施过程实际也面临 着农民难以接受, 政策落实力度不强, 监 管落实不到位等问题。

表 3 贵州省森林资源

\begin{tabular}{|c|c|c|c|c|c|c|}
\hline 指 标 & Item & 2012 & 2013 & 2014 & 2015 & 2016 \\
\hline $\begin{array}{l}\text { 森林面积 } \sigma \text { 万公 } \\
\text { 顷) }\end{array}$ & Forest Area(10000 Ha.) & 828.00 & 845.00 & 863.22 & 880.00 & 916.00 \\
\hline 森林覆盖率(\%) & Forest Coverage Rate (\%) & 47.00 & 48.00 & 49.00 & 50.00 & 52.00 \\
\hline $\begin{array}{l}\text { 森林蓄积量(亿立 } \\
\text { 方米) }\end{array}$ & Total Standing Forest Stock & 3.69 & 3.81 & 4.01 & 4.13 & 4.25 \\
\hline $\begin{array}{l}\text { 完成造林面积( 万 } \\
\text { 公顷) }\end{array}$ & $\begin{array}{l}\text { Area of Fulfilled } \\
\text { Forestation(10000 Ha.) }\end{array}$ & 19.93 & 21.82 & 30.27 & 28.00 & 35.20 \\
\hline $\begin{array}{l}\text { 封山育林面积 (万 } \\
\text { 公顷) }\end{array}$ & $\begin{array}{l}\text { Area of Seal Mountain Pass for } \\
\text { Forestation(10000 Ha. })\end{array}$ & 8.10 & 8.37 & 8.73 & 2.30 & 8.98 \\
\hline $\begin{array}{l}\text { 实施退耕还林工 } \\
\text { 程中: }\end{array}$ & $\begin{array}{l}\text { In Implement Cancel Infield for } \\
\text { Forest Project }\end{array}$ & & & & & \\
\hline $\begin{array}{l}\text { 宜林荒山造林(万 } \\
\text { 公顷) }\end{array}$ & $\begin{array}{l}\text { Forestation for Feasible deserted } \\
\text { Mountain( } 10000 \mathrm{Ha} \text {.) }\end{array}$ & 1.00 & 1.20 & 0.47 & 0.22 & \\
\hline $\begin{array}{l}\text { 天然林保护工程 } \\
\text { 中: }\end{array}$ & $\begin{array}{l}\text { In Savageness Forest Protect } \\
\text { Project }\end{array}$ & & & & & \\
\hline $\begin{array}{l}\text { 封山育林 (万公 } \\
\text { 顷) }\end{array}$ & $\begin{array}{l}\text { Seal Mountain Pass for Forestation } \\
(10000 \mathrm{Ha} \text {.) }\end{array}$ & 0.67 & 0.67 & 0.67 & 0.86 & 0.33 \\
\hline 森林保护 & Forest Protection & & & & & \\
\hline 森林火灾(起) & Forest Fire (unit) & 275 & 208 & 201 & 153 & 37 \\
\hline
\end{tabular}


生态扶贫的又一扶贫点在于增加护林 员岗位, 在保护森林果林的同时, 拉动就 业, 促进更多人脱贫。据贵州省政府发行 的《贵州省生态扶贫实施方案（20172020 年) 》政策来看, 新增护林员计划有 在现有生态护林员 4.47 万人基础上再新增 生态护林员 5.2 万人; 到 2020 年全省生态 护林员森林资源管护队伍总规模达 9.67 万 人, 人均管护森林面积稳定在 1500 亩以 内; 带动建档立卡贫困户 5.2 万户、 20 万人 人均增收 2300 元左右。

在以上统计数据基础上, 接下来本文 将选取其中部分数据作为指标, 运用 DEA 模型分析金融支持生态扶贫的成效分析。

\section{4. 基于 DEA 模型的生态扶贫成效研究}

数据包络分析 (Data Envelopment Analysis. DEA)[14]是针对每件有 “投入”与 “产出”的部门的决策行为, DEA 模型把每 一个相对应的“投入”——产出”看做一个决 策单元（Decision Making Unit. DMU）, 通 过数学模型对每个决策单元的相对有效性 进行评价。其实质是对 DMU 各“投入”与 “产出”按权分比例进行运算, 算出输出比投 入是几 $(\leq 1)$ 从而确定有效生产前沿面。 同时将 DMU 与前沿面进行比较, 确定各 DMU 是否 DEA 有效。

\section{1 指标的选取}

\section{1.1 投入指标}

(1)金融相关比率 (戈式指标) （X1）：即金融资产/GDP, 它可以表示金 融上层结构与经济基础结构之间在规模上 的关系, 用以表示金融规模程度。金融相 关比率在本文中使用年末存贷款额与 GDP 的比率。

(2)生态文明建设投入（X2）：各州市 一般公共预算支出中对“农林水事务”项目的 支出额。生态文明建设主要依靠政府的财 政支出, 财政支出预算中相关项目支出’额 和占比重可以直观的反映出政府对生态文 明建设的投入力度。

\section{1.2 产出指标}

(1)区域生产总值（Y1）：即各州市的 GDP, GDP 是目前认可度最高的衡量一个 国家或一个地区的经济发展水平的重要指 标, GDP 是作为产出指标的第一选择。

(2)城镇居民人均可支配收入（Y2）: 居民可支配收入是指居民户用于最终消费 支出和其他非义务性支出及储蓄的总和, 是衡量居民生活质量水平的重要指标。城 镇居民可支配收入可以作为产出指标之一 再按权重分配。

(3)农村居民人均可支配收入（Y3）： 居民可支配收入即居民家庭可以用来自由 支配的收入, 是衡量居民生活质量水平的 重要指标。将农村与城镇居民可支配收入 分开划分意义在于农村与城市收入差距 大, 应按不同权重比例分配, 从而准确得 到扶贫效果分析。

\section{2 样本的选取}

由于贵州省地理位置较为特殊, 部分 城市或州县可以依靠较好的位置条件与便 利的交通、实行生态扶贫, 建立生态产业 品牌, 而地理环境较差的城市则发展较为 困难, 扶贫效果相差很大。所以本文通过 查询 2017 贵州省年鉴数据, 选取了贵州 9 个州市的以上指标, 运用 DEA 分别对其进 行扶贫成效分析, 以观察各自效率高低。

\section{3 贵州省生态扶贫成效分析}

DEA 分析得到的数值范围均 $\leq 1$, 其中 出现 $<0$ 的部分使用修正的 DEA 进行评 测, 最终定义综合效率为 $\mathrm{h} 1$, 纯效率为 $\mathrm{h} 2$ 。通常情况对扶贫效率的梯度划分如表 4 所示, 当效率 $\mathrm{h}$ 在 $(0,0.5)$ 区间内时, 有相 当部分金融资产以及财政支出投入效率低 下; 当 $\mathrm{h}$ 处于 $[0.5,0.8)$ 区间内时, 表明资产 与财政支出已经有部分获得了较好的利 用, 但是仍有很大的改进空间; 当 $\mathrm{h}$ 处于 $[0.8,1)$ 区间内时, 表示资产与财政支出已经 获得了较为充分的利用; 当 $\mathrm{h}=1$, 扶贫成效 达到 DEA 有效水平, 投入指标完全获得充 分利用。 
表 4 扶贫效率梯度划分标准

\begin{tabular}{|c|c|c|c|c|}
\hline 效率值区间 & $0<\mathrm{h}<0.5$ & $0.5 \leqslant \mathrm{~h}<0.8$ & $0.8 \leqslant \mathrm{~h}<1$ & $\mathrm{~h}=1$ \\
\hline 融资效率等级 & 低效率 & 较低效率 & 较高效率 & 有效 \\
\hline
\end{tabular}

对贵州省 9 个地州市进行 DEA 成效测 度结果如表 5 所示。

由 DEA 成效分析结果可知,

除贵阳市和遵义市的金融对于生态扶 贫效率处于 DEA 较有效阶段, 其余 7 个地 州市均处于 DEA 无效水平。综合技术效率 $\mathrm{TE}$ 相较于纯技术效率 PTE 来说处于更低的
策推行等方面解释原因并给出改进建议。

\section{1 金融环境外部性问题}

贵州省处于我国西部, 目前是欠发达 地区, 经济水平在全国属于中下水平, 金 融行业的外部环境也相较其他金融发展较 快省份有明显不足。外部环境的落后导致

表 5 贵州省 9 个地州市 DEA 成效结果

\begin{tabular}{|c|c|c|}
\hline 地州市 & 综合技术效率 h1（TE） & 纯技术效率 h2 (PTE) \\
\hline 贵 阳 市 & 0.624 & 0.715 \\
\hline 六盘水市 & 0.399 & 0.349 \\
\hline 遵义市 & 0.539 & 0.629 \\
\hline 安 顺 市 & 0.176 & 0.311 \\
\hline 毕 节 市 & 0.437 & 0.527 \\
\hline 铜文市 & 0.377 & 0.419 \\
\hline 黔西南州 & 0.237 & 0.403 \\
\hline 黔东南州 & 0.424 & 0.420 \\
\hline 㛀 南 州 & 0.368 & 0.413 \\
\hline
\end{tabular}

层次。

从概念来看, 综合技术效率 $\mathrm{TE}$ 代表产 业结构能否符合总体要求并使之发挥最大 的成效和社会效益, 而纯技术效率 PTE 则 表示因为技术等因素影响的生态扶贫效 率。所以可知大部分地州市的金融支持生 态扶贫这一条路径整体并不完善, 很多环 节有缺失, 效率极低, 需要进一步完善金 融到支持生态扶贫的渠道以保证资本高效 利用。

（3）从纯技术效率 PTE 的表现来看, 虽然扶贫仍然处于 DEA 无效程度, 但是与 综合技术效率 TE 相比较高, 说明金融行业 与生态扶贫建设的改革和发展方向正确, 但扶贫综合成果要考虑到环境，政策等一 系列因素, 仍需积极探索适应贵州本地的 高效金融支持生态扶贫的策略。

\section{5. 金融发展对贵州生态扶贫成效的因素 分析}

以上通过 DEA 模型分析得到贵州省地 州市金融支持生态扶贫都无效率，本节将 试图从金融环境, 地理环境, 生态扶贫政
贵州省金融行业发展起步慢, 虽然目前以 较高增加率增长, 但是整体层次低, 种类 少, 例如表 1 所示外资银行目前只有花旗银 行一家。金融环境的外部性问题明显制约 了金融行业的发展, 并且应该通过积极推 动资本市场深化改革, 繁荣金融市场, 以 激活生态扶贫的“金融源泉”。

\section{2 地理环境因素}

生态扶贫是因地制宜发展当地特色生 态, 通过生态环境的建设反哺经济, 使得 当地贫困人口摘掉 “贫困” 的帽子。贵州 省政府通过发展还林护林, 进而形成果 林、森林公园等产业品牌的形式实施生态 扶贫战略。然而贵州省多山地, 大部分地 理环境较为恶劣, 在林业的种植上有一定 的困难; 打造成的品牌难以推销; 种植出 的果实难以外销或者外销成本极高都是制 约贵州省生态扶贫的一个重大因素。

\section{3 生态扶贫政策的推行实施}

退耕还林这一生态扶贫战略因为不能 立刻得到因发展林业而带来的实际收益, 
所以大部分农民会只看到眼前利益而不实 施或者消极实施, 因而政策在实行方面不 彻底也是影响生态扶贫效绩的直接原因。 同时, 在新增护林员岗位, 按亩补贴退耕 还林农户方面, 会大大增加政府的财政支 持, 维护政府财政收支稳定也是生态扶贫 战略实施过程中面临的重大挑战。

\section{参考文献}

[1] 陈述云, 刘带春. 金融发展与经济增长关 系: 来自西部贵州的实证. 统计研 究,2006(09):65-70.

２］屠亮. 贵州农村金融发展对农民收入影 响研究.贵州财经大学, 2012 .

[3] 周维. 贵州省金融发展与经济增长关系 的实证研究.贵州大学, 2015 .

[4] 杨文举.基于 DEA 的绿色经济增长核算: 以中国地区工业为例. 数量经济技术经 济研究,2011,28(01):19-34.

[5] 沈斌华. 谈 “生态扶贫” 和 “组织扶 贫”.北方经济, 1999(08):4-5.

[6] 杨文举,孙海宁.浅析城市化进程中的生 态环境问题.生态经济,2002(03):31-34.

[7] 查燕, 王惠荣, 蔡典雄, 武雪萍. 宁夏生态 扶贫现状与发展战略研究. 中国农业资 源与区划,2012,33(01):79-83.

[8] 刘慧, 叶尔肯 - 吾扎提.中国西部地区生 态扶贫策略研究.中国人口・资源与环 境,2013,23(10):52-58.

[9] 唐毓檚. 贵州省毕节市农村贫困研究.中 国农业科学院,2011.

[10] [崔艳娟. 我国金融发展对贫困减缓的影 响: 理论与实证.东北财经大学, 2012 .

[11] 张立军, 湛泳. 金融发展影响城乡收入差 距的三大效应分析及其检验. 数量经济 技术经济研究,2006(12):73-81.

[12] 沈茂英, 杨萍. 生态扶贫内涵及其运行模 式研究.农村经济,2016(07):3-8.

[13] 王小军.政策性银行支持生态扶贫的思 考.农业发展与金融,2017(12):39-42.

[14] Zhang H M, Chen Y Z, Wang Z. Research on the performance evaluation of government venture capital fund based on factor analysis and DEA model. Journal of Risk Analysis and Crisis Response, 2016, 6 (1) : 15-20. 